\title{
Time-sensitivity of the Kaiser effect of acoustic emission in limestone and its application to measurements of in-situ stress
}

\author{
Jin Yan*, Qi Zili, Chen Mian, Zhang Guangqing and Xu Guangqiang \\ Key Laboratory of Petroleum Engineering, Ministry of Education, China University of Petroleum, Beijing 102249, China
}

\begin{abstract}
Measuring in-situ stress by using the Kaiser effect in rocks has such advantages as timeefficiency, low cost and little limitation, but the precision of the method is dependent on rock properties and delay time of the measurement. In this paper, experiments on the Kaiser effect in limestones were performed, and it was found that the limestones had good ability to retain a memory of their recent stress history and high time-sensitivity. The longer the experiment was delayed from the extraction of the stone, the larger the Felicity ratio was. As the Felicity ratio approached 1, significant Kaiser effect was observed. In-situ stress should be determined by the limestone measurements when the delay time was 40-120 days. Finally, the in-situ stress in a limestone formation could be successfully measured in practice.
\end{abstract}

Key words: In-situ stress, Kaiser effect, limestone, time sensitivity

\section{Introduction}

In China, abundant oil and gas have been discovered in limestone reservoirs, but their buried depths are commonly greater than $1,000 \mathrm{~m}$. In-situ stress plays a key role in the exploration and development of oil and gas reservoirs. The acoustic emission technique is an important method of measuring the in-situ stress in limestone formations. Research has been done to measure the rock stress by using acoustic emission. The Kaiser effect was firstly observed in the early 1950s (Kaiser, 1953). In 1963, Goodman proposed that the Kaiser effect of acoustic emission also existed in rocks (Goodman, 1963). The Kaiser effect has been used to determine in-situ stress since the 1970s (Tanimoto et al, 1978). Boyce (1991) investigated the maximum historical stress in many types of rocks by using the acoustic emission method. Michihiro (1991) proposed that rock memorized the maximum historical strain better than the maximum historical stress. Li and Norlund (1993) presented a method of estimating rock damage by using acoustic emission based on experimental results. Cox and Meredith (1993) studied the relationship between the formation of microcracks, material softening in rocks and acoustic emission. Chen et al presented a new method of measuring in-situ stress, which combines acoustic anisotropy and the Kaiser effect under confining pressure (Shi et al, 2004). Unlike conventional methods, this new method does not require high-standard test core, the horizontal principal in-situ stress can be measured from a core with less than $4 \mathrm{~cm}$ in thickness, providing a new way to measure the in-situ stress at a great depth. Deng et al (1997)

*Corresponding author. email: jiny@cup.edu.cn

Received April 28, 2008 believed that the Kaiser effect is related to rock properties, and test cores should be treated by the wax-sealed after coring and should be tested within one year. Furthermore, the core specimens must have high strength and low porosity. Barr and Hunt (1999) have studied the anelastic strain recovery and the Kaiser effect retention span of granite and the behavior was modeled by using both the Kelvin and Burger rheological models. They suggested that it requires a specific period of time for the recovery of the anelastic strain. This phenomenon is called the anelastic effect, and this effect is especially obvious in low-stress cases. Zhu et al (2002) simply analyzed the time effect on acoustic emission. Xie et al (2002) investigated the acoustic emission of limestone under uniaxial compression, and they found that the main reasons for acoustic emission in the stone are the formation of new microcracks and propagation of original cracks. Li and Zhou (2004) tested and analyzed acoustic emission characteristics of four types of rocks under uni-axial compression. Li et al (2006) obtained the state parameters, physical parameters, and acoustic emission signals through experiments. Also, the relations between acoustic emission counts and stress, strain, damage factor under different loading conditions were analyzed in detail.

The Felicity effect is the appearance of significant acoustic emission at a stress level below the previous maximum value, which is due to the redistribution of stress in the rock mass, and new deformation and fracture propagation in the rocks during the reloading test. The Felicity ratio, $F R\left(P_{\mathrm{AE}} / P_{\max }\right)$, which is defined as the ratio of acoustic emission onset stress value $\left(P_{\mathrm{AE}}\right)$ during a reloading test to the previous peak value $\left(P_{\max }\right)$, can reflect the precious damage and structure defects of the material (Li and Norlund,1993).

The Felicity effect is a supplement of the Kaiser effect, 
and moreover the Felicity ratio can be used as a measurement of the degree of Kaiser effect failure. If $F R<1$, the Felicity effect exists; and if $F R>1$, the Kaiser effect exists. The more $F R$ approaches 1 , the better the ability of stress memory is. Generally, the smaller the Felicity ratio is, the worse the damage or defect is. Meantime, the Felicity ratio also reflects the accuracy of the Kaiser effect.

Due to all the above results we can predict that the precision of using the Kaiser effect method to measure in-situ stress in deeply buried depth rock is dependent on the delay time of the measurement. In this paper, experiments of the Kaiser effect were performed on samples taken from deeply buried limestone. This paper focuses on time-sensitivity of the Kaiser effect of limestone. The experimental results were then used to estimate the in-situ stress in practice.

\section{Experimental}

\subsection{Specimen preparation}

All the core specimens in the tests were taken from a limestone formation of $920 \mathrm{~m}$ depth, with vertical stress of 20.02 MPa, in the Changqing Oilfield, China. The specimens were $25 \mathrm{~mm}$ in diameter and $38-50 \mathrm{~mm}$ in length. The sampling aligns with the axis of a large core. The parameters of the specimens are shown in Table 1.

Table 1 Specimen parameters

\begin{tabular}{cccc}
\hline Number & $\begin{array}{c}\text { Diameter } \\
\mathrm{mm}\end{array}$ & $\begin{array}{c}\text { Length } \\
\mathrm{mm}\end{array}$ & $\begin{array}{c}\text { Time delay } \\
\text { day }\end{array}$ \\
\hline H1 & 25.26 & 43.40 & 7 \\
H2 & 25.18 & 40.28 & 14 \\
H3 & 25.09 & 49.84 & 30 \\
H4 & 25.28 & 41.50 & 60 \\
H5 & 25.22 & 38.62 & 180 \\
\hline
\end{tabular}

\subsection{Equipment and method}

The equipment used included an MTS-816 rock testing system, MTS-286 servo loading system, and SAMOS acoustic emission monitoring system (Fig. 1). The loading process was controlled by force mode and the loading rate was $0.7 \mathrm{kN} / \mathrm{min}$. The stress corresponding to the occurrence of the Kaiser effect was recorded. After measurement, the specimen was unloaded down to zero.

\section{Experimental results and discussion}

In order to acquire the variation characteristics of acoustic emission signals in the limestone, the cumulative acoustic emission number (cumulative AE counts) and the signal intensity of acoustic emission (AE hits) were analyzed. Experimental results are shown in Fig. 2.

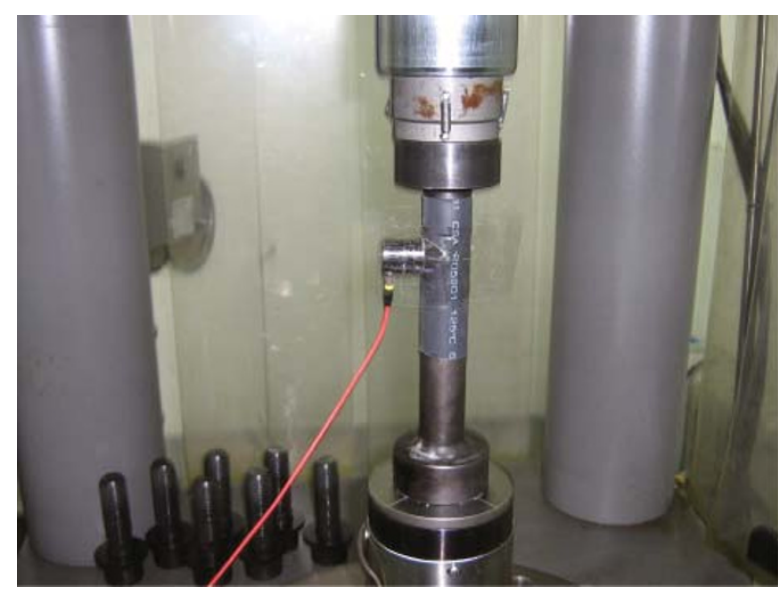

Fig. 1 Experimental equipment

The Kaiser effect is considered to occur when the cumulative $\mathrm{AE}$ counts and $\mathrm{AE}$ hits increase dramatically. From cumulative AE counts-stress and AE hits-stress curves, the Kaiser points can be identified, as shown by the arrows in Fig. 2.

Fig. 2 indicates that a significant Kaiser effect was observed when the delay time is 60 days (see Fig. 2d). The cumulative emission number and the signal intensity of acoustic emission increased abruptly when the load reached $20 \mathrm{MPa}$. On the other hand, the Kaiser effect was quite ambiguous when the delay time was 7,14, and 180 days, respectively (see Fig. 2a, 2b, 2e). The Kaiser point was hard to identify. The relative error could be $9 \%$ when one determined the Kaiser point approximately (see Fig. 3 and Table 2). Therefore, the Kaiser effect was influenced by the delay time. The longer or the shorter the experiment is delayed from the extraction of the core, the larger the uncertainty in determining the Kaiser point. From the limited experiments here on one limestone sample, it seems possible the delay time should be near 60 days when the Kaiser effect is used to measure the in-situ stress in practice.

From Fig. 3 and Table 2, the Felicity ratio increased from 0.91 to 1.10 with delay time from 7 to 180 days, while Kaiser stress changed from 18.25 to $22.07 \mathrm{MPa}$. During the first 30 days and beyond 120 days, a significant Felicity effect was observed. The damage to the test specimen, i.e. different scales of fractures, was induced by in-situ stress. When the specimen was reloaded in the laboratory, new damage occurred in the specimen as the load approached the maximum normal stress underground, then the Kaiser effect appeared. Limestone can memorize the pre-stress applied to the rock through rhetorical damage. Limestone has high strength and self-recovering ability. During the first 30 days, a significant Felicity effect was observed (Fig. 3), in other words, in the first 30 days the unstable damage to the limestone could be slowly recovered, so the acoustic emission signal was disordered, and it was difficult to identify the Kaiser effect. As the unstable damage was recovered about 60 days later, $F R$ approached 1, and a significant Kaiser effect was observed. As the limestone has the ability to recover its interior damage 180 days later, $F R$ was more than 1.1, and it was difficult to determine the Kaiser effect. The longer the 

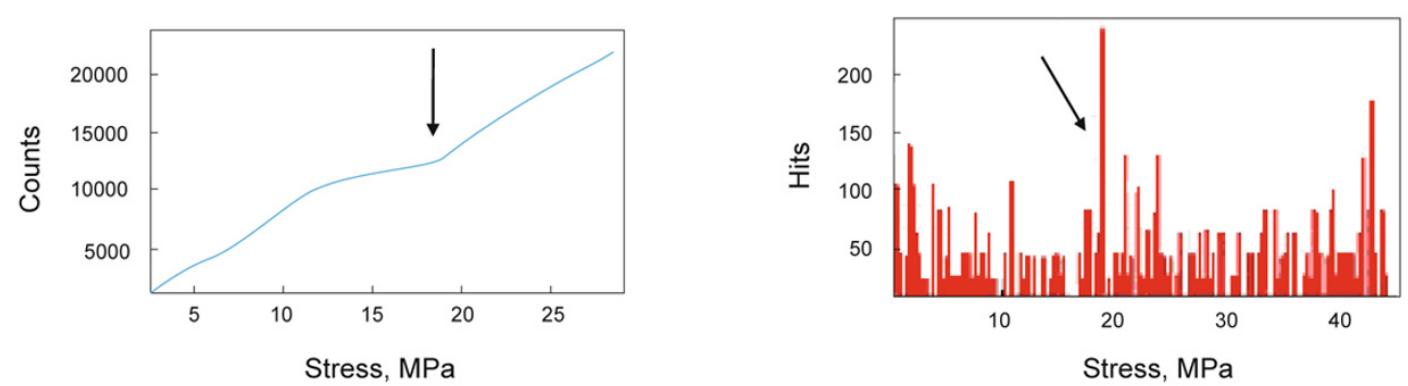

(a) Specimen $\mathrm{H} 1$
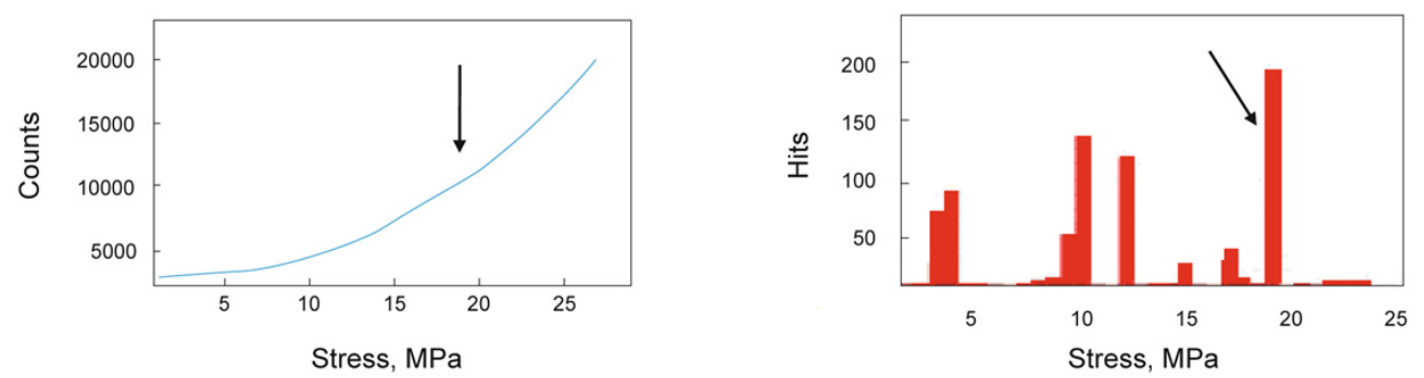

(b) Specimen $\mathrm{H} 2$
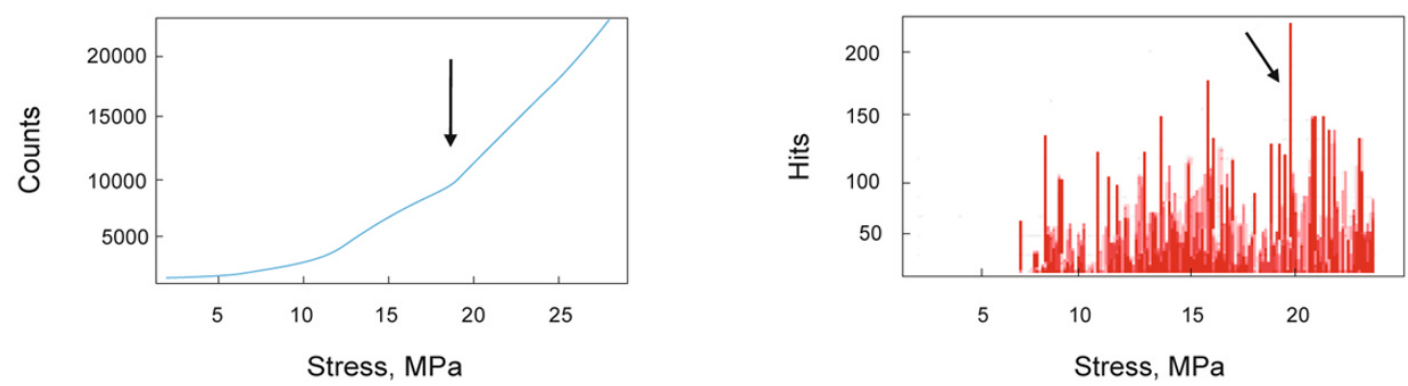

(c) Specimen $\mathrm{H} 3$
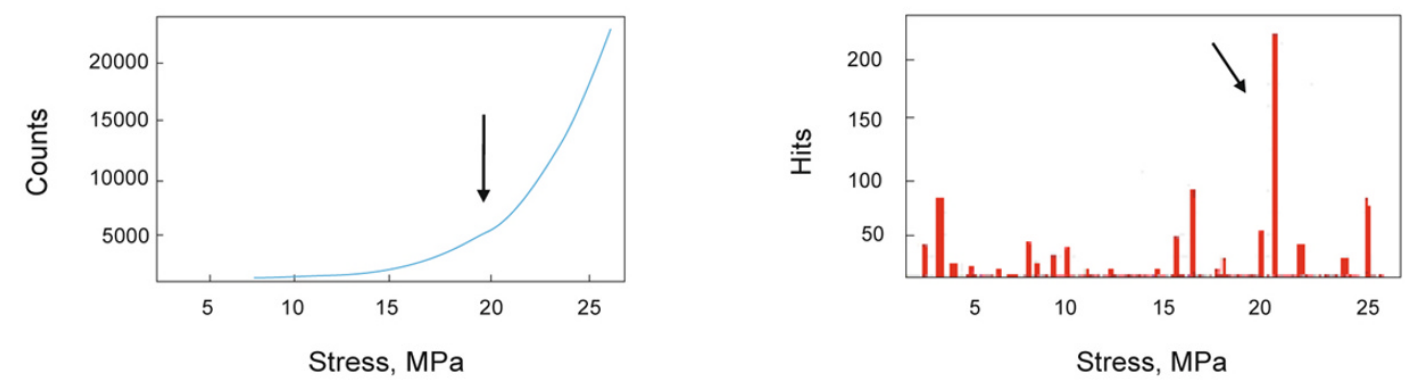

(d) Specimen $\mathrm{H} 4$
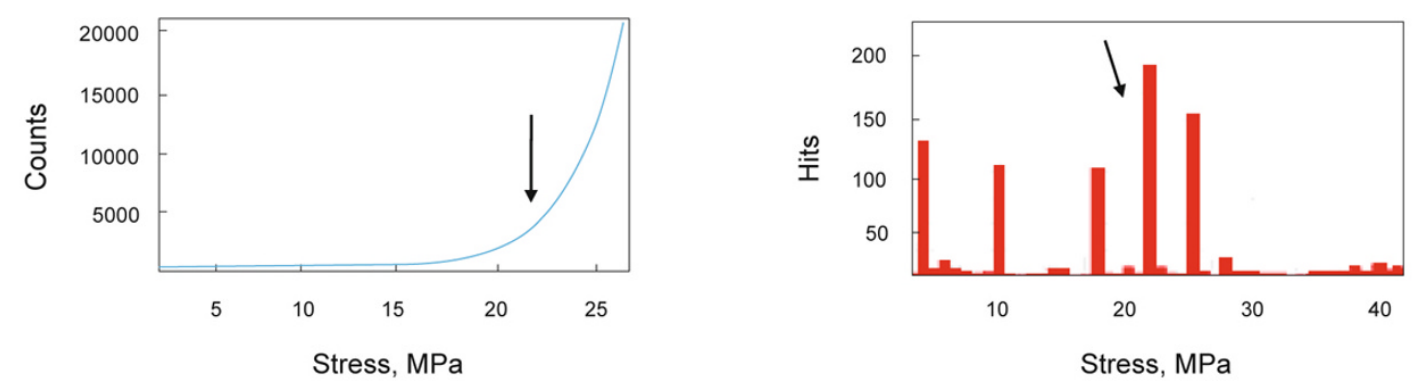

(e) Specimen $\mathrm{H} 5$

Fig. 2 Cumulative AE counts and hits versus stress 
Table 2 Variation of Kaiser stress and Felicity ratio with delay time

\begin{tabular}{ccccc}
\hline Number & Delay time, day & Kaiser stress, MPa & Stress relative error, $\%$ & Felicity ratio (FR) \\
\hline H1 & 7 & 18.66 & -7.41 & 0.931 \\
H2 & 14 & 18.25 & -9.83 & 0.911 \\
H3 & 30 & 19.37 & -3.46 & 1.005 \\
H4 & 60 & 20.15 & 0.54 & 1.101 \\
\hline
\end{tabular}

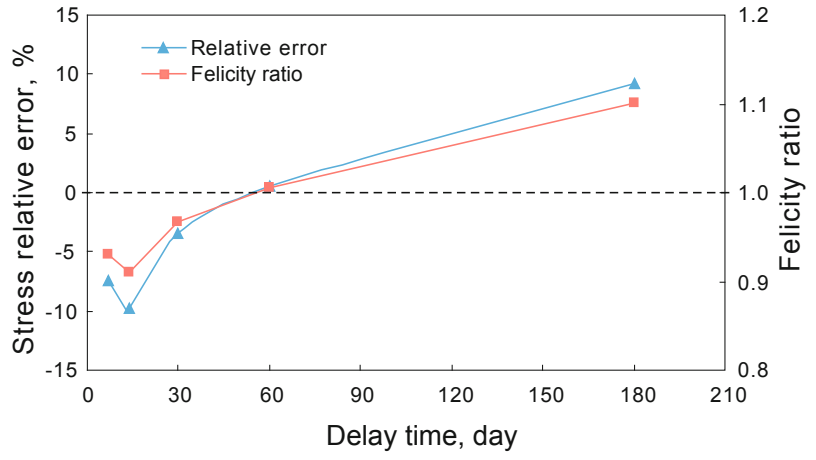

Fig. 3 Variation of stress relative error and Felicity ratio with delay time

delay time was, the greater the difficulty in determining the Kaiser effect. From this small experiment on one limestone sample, local stress should be determined by the limestone measurements when the delay time is $40-120$ days.

\section{Measurement of in-situ stress}

The test specimens were cut from a piece of large limestone core (Fig. 4), which was taken from an interval of 1,950-1,966 m in Well Yuan-115 in the Changqing Oilfield, China. The sampling directions were 0,45 and 90 degrees, as shown in Fig. 5. The time delay was 4 months and 12 days from the extraction of the core to the experimental test. The uni-axial compressive strength of the limestone was 91.31 MPa. The loading was controlled by force mode and the loading rate was $0.7 \mathrm{kN} / \mathrm{min}$.

Using the Kaiser effect, the maximum stress undergone previously in the axial direction was determined for the test core specimens, and the in-situ stress could be calculated from Eqs. (1) through (4) proposed by Deng et al (1997), as shown in Table 3. In our calculations, the effective stress factor and pore pressure used were 0.83 and $15 \mathrm{MPa}$, respectively. The experimental results in Table 3 were in agreement with the results measured by mini-fracturing test.

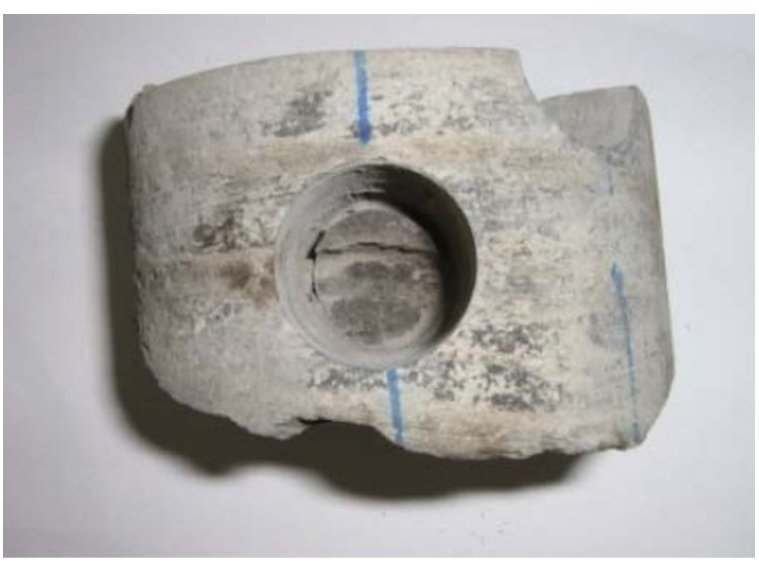

Fig. 4 The large core from Changqing Oilfield

Table 3 Measured in-situ stress for Well Yuan-115 in Changqing Oilfield

\begin{tabular}{|c|c|c|c|c|c|}
\hline \multirow{2}{*}{ Specimen } & \multicolumn{3}{|c|}{ Kaiser effect method } & \multicolumn{2}{|c|}{ Mini-fracturing test } \\
\hline & $\begin{array}{c}\text { Kaiser stress } \\
\mathrm{MPa}\end{array}$ & $\begin{array}{c}\text { Maximum stress } \\
\mathrm{MPa}\end{array}$ & $\begin{array}{c}\text { Minimum stress } \\
\mathrm{MPa}\end{array}$ & $\begin{array}{c}\text { Maximum stress } \\
\mathrm{MPa}\end{array}$ & $\begin{array}{c}\text { Minimum stress } \\
\mathrm{MPa}\end{array}$ \\
\hline S0 & 36.96 & & & & \\
\hline S45 & 43.31 & 42.04 & 36.73 & 43.36 & 37.07 \\
\hline S90 & 41.81 & & & & \\
\hline
\end{tabular}




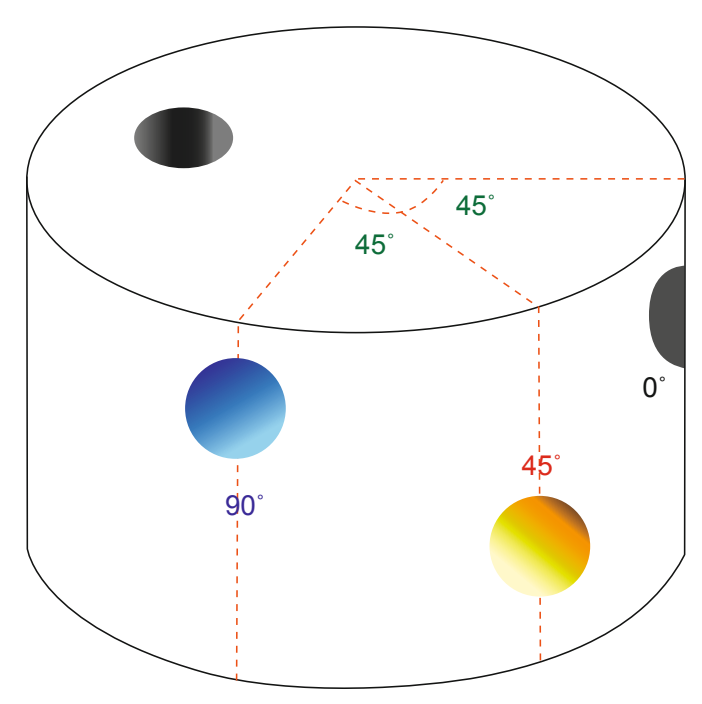

Fig. 5 Sketch diagram of coring directions

\section{Conclusions}

1) The Kaiser effect of limestone is highly time-sensitive. Significant Kaiser effect can be observed when the delay time is near 60 days, but the Kaiser effect is quite ambiguous when the delay time is within 30 days or beyond 180 days.

2) The buried rock has undergone in-situ stress and there is different degrees of damage, and the extracted core has the ability to recover its interior damage. The longer the experiment is delayed from the extraction of the limestone, the larger the Felicity ratio is. There is uncertainty in determining the Kaiser effect as the delay time is too short or too long. The delay time of 40-120 days is a reasonable period.

3) The limestone has good ability to retain a memory of its recent stress history underground with high precision. The acoustic emission method, in application to measuring in-situ stress, has advantages such as time-efficiency, low cost, and little limitation.

\section{References}

Barr S P and Hunt D P. Anelastic strain recovery and the Kaiser effect retention span in the Carrmenellis Granite. Rock Mechanics and Rock Engineering. 1999. 32(3): 169-193

Boyce G M. A study of the acoustic emission response of various rock types. Master Thesis. Drexel University. 1991. 46-70

Cox S J D and Meredith P G. Microcrack formation and material softening in rock measured by monitoring acoustic emissions. International Journal of Rock Mechanics and Mining Sciences. 1993. 30(7): 11-24

Deng J G, Huang R Z and Tian X S. A new method for measuring in-situ stress in deep formation. Journal of University of Petroleum, China. 1997. 21(1): 32-35 (in Chinese)

Goodman R E. Subaudible noise during compression of rocks. Bulletin of the Geological Society of America. 1963. (74): 487-490

Kaiser E J. A study of acoustic phenomena in tensile test. Doctoral Thesis. Technische Hochschule München. 1953

Li C and Norlund E. Experimental verification of Kaiser effect in rocks. Rock Mechanics and Rock Engineering. 1993. 26(4): 333-351

Li J P and Zhou C B. Experimental research on acoustic emission characteristics of rock mass. Rock and Soil Mechanics. 2004. 25(3): 374-378 (in Chinese)

Li Y H, Yuan R F and Zhao X D. Research on ability to memorize previous load by AE testing in rock. Journal of Liaoning Technical University. 2006. 25(4): 518-520 (in Chinese)

Michihiro K. Study on estimating stresses by Kaiser effect. Proc. 26th US Symposium on Rock Mechanics. Chicago: Trans. Tech. Pub. 1991. 981-992

Shi L, Zhang X D, Jin Y, et al. New method for measurement of insitu stresses at great depth. Chinese Journal of Rock Mechanics and Engineering. 2004. 23(14): 2355-2358 (in Chinese)

Tanimoto K, Nakamura J and Fudo R. Application of acoustic emission in in-situ test. In: Proceedings of the 10th International Conference on Soil Mechanics and Foundation Engineering. Rotterdam: Balkema A A. 1978. 573-576

Xie Q, Zhang Z X and Yu X B. Limestone acoustic emission under the condition of uni-compression. Journal of Chongqing University of Construction, China. 2002. 24(1): 21-24 (in Chinese)

Zhu F C, Pan C L, Cao P, et al. Rock acoustic emission and its application in in-situ stress measurement. Foreign Metal Mining Magazine. 2002. 2: 13-15 (in Chinese)

(Edited by Sun Yanhua) 